\title{
MUSIK INDIE SEBAGAI PRAKTIK PERLAWANAN TERHADAP RENCANA REKLAMASI TELUK BENOA, BALI
}

\author{
I Dewa Gede Kusuma \\ Fakultas Ilmu Sosial dan Ilmu Politik Universitas Mahendradatta - Denpasar \\ email: dewakusuma44@yahoo.com
}

\begin{abstract}
Abstrak- Penelitian ini menganalisis gerakan musik indie sebagai gerakan antireklamasi Teluk Benoa, Kabupaten Badung, tahun 2013-2018. Ada tiga masalah yang dikaji dalam penelitian ini, yaitu representasi musik indie sebagai praktik perlawanan terhadap rencana reklamasi Teluk Benoa, ideologi yang melatarbelakangi musik indie dalam praktik perlawanan terhadap rencana reklamasi Teluk Benoa, dan signifikansi praktik perlawanan musik indie terhadap rencana reklamasi Teluk Benoa. Penelitian ini menerapkan metode kualitatif dengan teknik pengumpulan data dengan wawancara, studi dokumen, dan observasi.Data yang terkumpul dianalisis dengan menggunakan teori Kuasa Pengetahuan, Praktik, dan Semiotik.

Analisis ini menghasilkan tiga simpulan.Pertama, dalam gerakannya menolak rencana reklamasi Teluk Benoa, musik indie berusaha merepresentasikan aspirasi rakyat lewat lirik-lirik lagunya yang dipentaskan dalam demo-demo antireklamasi.Lewat artikulasi pesan antireklamasi musik indie, masyarakat merasa terwakili aspirasinya dalam lagu musik indie.Kedua, ideologi yang mendasari gerakan musik indie Bali antireklamasi adalah ideologi pelestarian lingkungan dan budaya. Lirik-lirik lagu musik indie mengartikulasikan bahwa reklamasi akan merusak lingkungan dan tidak menghormati budaya Bali. Ketiga, signifikansi praktik perlawanan musik indie terlihat dari semakin intensnya aspirasi masyarakat meminta Perpres Nomor 51 Tahun 2014 segera dibatalkan sehingga rencana reklamasi bisa dibatal.
\end{abstract}

\section{Kata kunci:musik indie, perlawanan, reklamasi Teluk Benoa}

Abstract- This study aimed at analyzing indie music movement as an anti-reclamation movement at Benoa Bay, Badung Regency, in 2013 - 2018. There were three problems analyzed in this study; the representation of indie music as a resistance practice towards Benoa Bay reclamation plan, the ideology behind the music as a resistance practice towards Benoa Bay reclamation plan, and the significance of the resistance practice towards Benoa Bay reclamation plan. This study applied qualitative method with interviews, document studies and observation as techniques of collecting data. The obtained data were analyzed by using the theories of Knowledge Power, Practice and Semiotics.

There were three conclusions drawn from the analysis. Firstly, in its movement of refusing reclamation plan at Benoa Bay, the indie music made efforts to represent people's aspirations through the lyrics of the songs performed in the anti-reclamation demonstrations. Through the articulation of the anti-reclamation message in music, the people felt that their aspirations were represented in the music. Secondly, the ideology behind the anti-reclamation 
movement was environmental conservation ideology and culture. The lyrics of the songs articulated that the reclamation would damage the environment and disrespectful to the Balinese culture. Thirdly, the significance of the indie music's resistance practice was seen from the intense aspirations from the people to cancel Presidential Regulation 51 in 2014, so that reclamation plan could be cancelled.

\section{Keywords: indie music, resistance, Benoa Bay Reclamation}

\section{Pendahuluan}

Gerakan Bali Tolak Reklamasi (BTR) tahun 2013 s.d. 2018 diikuti berbagai lapisan masyarakat Pasubayan Desa Adat, aktivis lingkungan, seniman, dan musisi musik indie. Segera setelah isu reklamasi di Teluk Benoa mencuat tahun 2013, orang-orang bergerak menolak dengan menyebarluaskan perlawanan melalui lagu berjudul "Bali Tolak Reklamasi”, lagu dimaksud dinilai mampu mempengaruhi generasi muda di Bali, untuk menolak reklamasi. Grup band yang turun ke dalam demonstrasi BTR, yaitu Superman Is Dead (S.I.D), Navicula, The Hydrant, Scared of Bums (S.O.B), Nosstress, The Dissland, dan lainnya.

Gerakan BTR ini meluas ke sejumlah wilayah di Bali Selatan.Pihak investor pengembang PT TWBI terhalang oleh aspek sosial-budaya masyarakat Bali yang cukup kuat. Namun demikian, masyarakat penolak reklamasi Teluk Benoa mengetahui bahwa Perpres Nomor 51 Tahun 2014 yang diterbitkan pada saat pemerintahan Presiden RI keenam Susilo Bambang Yudhoyono
(SBY), hingga akhir tahun 2018 ternyata belum ada dicabut oleh Presiden RI ketujuh Joko Widodo.

Gerakan BTR berjalan masif antara tahun 2013-2018.Data diperolehdari Forum Rakyat Bali Tolak Reklamasi (ForBALI) terdapat 64events musik BTR yang dirilis mulai tahun 2013.Gerakan BTRdidukung kalangan musisi indie sekaligus juga cukup efektif menyebarkan pemahaman Bali Tolak Reklamasi-Batalkan Perpres Nomor 51 Tahun 2014.

Kerjasama antara musisi dan seluruh penggemar indie lahir spontanitas sebagai satu rasa kegelisahan bahwa kondisi alam Bali 'tidak sedang baik-baik saja'. Kalangan investor pengembang PT TWBI, bersama kroni-kroni pendukung reklamasi terganjal oleh aksi penolakan Pasubayan Desa Adat.Dukungan BTR berlipat ganda mencapai ribuan orang dari masyarakat desa adat di Bali Selatan dan sekitarnya.

Gerakan perlawanan BTR tidak lagi terkesan menoton, melalui konser mini yang 
dipadu kolaborasi band-band indie membuat atmosfer gerakan BTR menjadi lebih kuat dan menggembirakan.Konser mini yang melibatkan musisi musik indie kenamaan di Bali,dilakukanberkesinambungan besertamengambil lokasi strategis di sejumlah titik wantilanbale banjar, jalan di depan Kantor Gubernur Bali pada saat demo BTR, bar umum, serta panggung-panggung kesenian lainnya di Bali.

Pemprov Bali mengeluarkan dua SK, pertama, SK 2138/02-C/HK/2012 tentang Pemberian Izin dan Hak Pemanfaatan, Pengembangan dan Pengelolaan Wilayah Perairan Teluk Benoa Provinsi Bali, yang ditetapkan di Denpasar pada 26 Desember 2012. Kedua disusul dengan SK 1727/01B/HK/2013 tentang Izin Studi Kelayakan Rencana Pemanfaatan, Pengembangan dan Pengelolaan Wilayah Perairan Teluk Benoa, yang manaditetapkan di Denpasar pada 16 Agustus 2013.

Isu BTR tidak berhenti di sana saja, pemerintah pusat ketika era Presiden RI keenam SBY, lalu mengeluarkan Perpres Nomor 51 Tahun 2014 tentang Perubahan Atas Peraturan Presiden Nomor 45 Tahun2011Tentang Rencana Tata Ruang Kawasan Perkotaan Denpasar, Badung, Gianyar, dan Tabanan, yang ditetapkan di
Jakarta30 Mei 2014dengan peruntukan rencana reklamasi mencapai luas $700 \mathrm{Ha}$.

Seminggu sekali rutin digelar eventstolak reklamasi melalui gerakan BTR yang didukungkalangan musisi, aktivis, seniman, Pasubayan Desa Adat, dan masyarakat umum. Rencana reklamasi seluas 838 Ha mampu ditekan menjadi seluas 700 Ha.Pentas musik indie masih berlanjut di tahun 2019, untuk berjuang supaya Perpres Nomor 51 Tahun 2014dicabut oleh pemerintahdi pusat.Pada prinsipnya, penelitian ilmiah terkait Teluk Benoa, menyatakan bahwa Teluk Benoa ini "tidak layak" untuk direklamasi berdasarkan aspek-aspek sosial-budaya.

Masalah yang dikaji dalam penelitian dituangkan pada tiga pertanyaan, pertama,bagaimana representasi musik indie sebagai praktik perlawanan terhadap rencana reklamasi Teluk Benoa. Kedua, ideologi apa yang melatarbelakangi musik indie dalam praktik perlawanan terhadap rencana reklamasi Teluk Benoa. Berikutnya, ketiga, bagaimana signifikansi praktik perlawanan musik indie terhadap rencana reklamasi Teluk Benoa.

Penelitian secara umum bertujuan agar memahami representasi musik indie sebagai praktik perlawanan terhadap rencana reklamasi Teluk Benoa.Memahami ideologi 
yang melatarbelakangi musik indie dalam praktik perlawanan terhadap rencana reklamasi Teluk Benoa.Selanjutnya, memahami signifikansi praktik perlawanan musisi musik indie terhadap rencana reklamasi Teluk Benoa. Gerakan BTR, dilakukan secara kolektif melalui kreativitas konser mini BTR, diskusi ilmiah, beserta demonstrasi secara tertib.

Penelitian kualitatif menggunakan pendekatan poststruktural yang melihat masalah secara kritis.Hasil penelitian ini kemudian disajikan peneliti secara deskriptif interpretatif dalam bentuk kata-kata serta bahasa.Lokasi objek penelitian berada di daerah Bali Selatan.Subjek penelitian dipilih beberapa orang musisi yang aktif di dalam demonstrasi untuk menolak rencana reklamasi Teluk Benoa.Narasumber dipilih dari supra desa (luar desa) yang berperan andil, mobilitas tinggi, dan kewenangan memonitoring persoalan di wilayah tertentu, khususnya terkait tesis.

Sedangkan, jenis data-data kualitatif yang digunakan serta dituangkan ke dalam sebuah narasi. Sumber data-data penunjang lainnya hasil dari observasi lapangan musik indie, wawancara personel band, audiens musik indie, tokoh-tokoh Pasubayan Desa Adat, aktivis lingkungan, dan pejabat terkait di tingkat Pemprov Bali. Sumber data lainnya adalah hasil rekaman suara yang dikumpulkan dari orasi aktivis lingkungan pada saat demo BTR. Hasil dari wawancara dengan informan merupakan data primer yang dikelola dan selanjutnya digambarkan secara deskriptif.Selanjutnya, studi pustaka sebagai data sekunder untuk pengembangan dan juga pemahaman terhadap objek-objek yang disajikan secara deskriptif.

Instrumen penelitian menggunakan pedoman pertanyaan (interview guide), sedangkan teknik pengumpulan data dengan a) wawancara, b) observasi, dan c) studi dokumen. Penelitian informan dilakukan dengan sifatnya berlanjut terus (snowball), berdasarkan petunjuk dari satu informan hingga menemukan titik jenuh informasi.

Analisis data penelitian dilakukan secara deskriptif kualitatif dan interpretatif sesuai atas data-data terkumpul.Kemudian diproses melalui penyederhanaan, penyajian data, dan penafsiran simpulan.

\section{Konsep}

Dalam penelitian ini dikemukakan konsep yang memiliki relevansi definisi operasional penelitian, yaitu musik indie, praktik perlawanan, dan reklamasi Teluk Benoa yang dijelaskan ke dalam batasan konsep-konsep berikut ini. 


\section{a. Musik Indie}

Indie berasal dari kata independent, tetapi wajib dibedakan antara independent sebagai status artis, band, atau minor label yang mana tidak dikuasai atau dikendalikan major label dan independent di dalam konteks indie sebagai subkultur serta genre musik. Musik indie merupakan aliran atau genre musik yang "not even exist”, karena yang disebut musik indie itu adalah untuk membedakan antara yang mainstream dengan indie. Musik indie adalah istilah untuk membedakan antara musik yang dimainkan oleh musisi profesional dengan musisi amatir. Akan tetapi, yang pasti indie adalah gerakan bermusik yang berbasis dari apa yang kita punyai, do it yourself, etika yang dimiliki dimulai dari proses merekam, mendistribusikan, dan selanjutnya promosi menggunakan uang sendiri.

Secara umum yang dimaksud dengan mainstream sebagai arus utama, tempat di mana grup band-band yang bernaung di bawah label besar, dan merupakan sebuah industri yang mapan. Band-band tersebut dipasarkan secara meluas yang coverage promosinya juga luas, nasional maupun internasional, dan mereka mendominasi promosi di seluruh media massa, mulai dari media cetak, media elektronik hingga multimedia (Jube, 2008: 33-34).

Band-band indie mengalami suatu segmentasi perubahan seiring perkembangan teknologi dan alat musik modern. Cukup banyak band-band indie mengumpulkan isi dan lirik lagu, namun karya yang mereka luncurkan belum bisa seluruhnya digemari anak muda. Dengan kata lain, pendengar di era tahun 2017 ke atas sudah semakin cerdas menilai single yang dilantunkan personel band. Berbeda terhadap grup band yang telah memiliki nama besar, seperti S.I.D, Navicula, The Hydrant, Scared of Bums (S.O.B), The Dissland, dan Nosstress band, mereka hanya tinggal mempertajam 
kualitasisi lirik dan lagu perlawanan dibuat terhadap gerakan BTR.

Musisi indie mendukung gerakan BTR Teluk Benoa, sebagai suatu simbol perlawanan masyarakat Bali Selatan atas Perpres Nomor 51 Tahun 2014. Dukungan penolakan musisi indie, mempengaruhi counter korporasi investor pengembang di dalam memandang strategi sosial Pasubayan Desa Adat. Rencana untuk menimbun Teluk Benoa oleh investor PT TWBI, akhirnya mendapat penolakan Pasubayan Desa Adat secara berkesinambungan.Sampai saat ini, pemerintah pusat belum ada bersikap atas konsistensi gerakan BTR.

\section{b. Praktik Perlawanan}

Berada di jalur indie atau masuk ke major label adalah mutlak pilihan musisi. Namun, idealisme musisi di Bali, dalam melawan investor PT TWBI, mereka lebih mudah bersatu terkait hal-hal menyangkut masa depan alam di Teluk Benoa. Simbol gerakan perlawanan musik indie disisipkan di atas panggung konser.Personel band sering mengenakan atribut kaos BTR dan juga membawa bendera ForBALI pada saat konser.Baju kaos dikenakan dan bendera dikibarkan merupakan simbol gerakan BTR, yang mana terus digaungkan serius musisi demi melawan rencana reklamasi.

Hal tersebut menunjukkan bahwa personel band indie tidak saja bicara tentang pentas musik, melainkan turut berperan untuk menyebarluaskan ideologi perlawanan BTR Teluk Benoa kepada penggemarnya. Gerakan BTR Teluk Benoa ini berjalan masif dengan dukungan penuh dari musisi indie, melalui perlawanan kreatif musisi indie, mereka berupaya Perpres Nomor 51 Tahun 2014 agar dibatalkan pemerintah pusat. Bagi investor pengembang, gerakan perlawanan BTR dimaksud justru dianggap menghambat realisasi pulau-pulau baru di Teluk Benoa. 


\section{c. Reklamasi Teluk Benoa}

Sejumlah wilayah di Bali dibangun melaluireklamasi, seperti proses pembangunan Bandara I Gusti Ngurah Rai. I Made Nariana menyebutkan bahwa kalau tidak demikian, Pulau Bali sudah semakin mengecil digerus ombak yang semakin menganas. Lalu mengapa sekarang orang ribut soal reklamasi Teluk Benoa, bagi Nariana ia melihat hanya persoalan rezeki. Pertama, sejumlah perusahaan ingin melakukan hal yang sama, maka perusahaan yang tidak mendapat berusaha untuk menghalangi.

Kedua, ada pihak-pihak lain yang ingin terlibat sebagai bagian terkait dalam proyek. Karena tidak terakomodasi berusaha memprovokasi orang lain supaya menolak. Ketiga, hanya ingin mengagalkan ide orang lain membuat Bali lebih bersih, rapi, dan cantik khususnya ditinjau dari segi kepariwisataan. Hanya dengan beralasan akan merusak Bali, tidak sesuai adat budaya, kekhawatiran yang berlebihan, tidak mau memandang jauh ke depan, mereka menolak reklamasi Teluk Benoa. Belum ada sejarah yang mengatakan, sebuah pulau tenggelam di dunia karena reklamasi. Negara seperti Belanda, Singapura, Jepang, Malaysia, Australia, Dubai, termasuk Ibukota Jakarta melakukan reklamasi guna menambah objek wisata yang menarik (Nariana, 2015: 88-89).

Nariana berpandangan bahwa isu rencana reklamasi Teluk Benoa, dengan fakta reklamasi di beberapa negara bukan sebagai persoalan. Namun demikian, di Bali Selatan rencana reklamasi banyak ditentang Pasubayan Desa Adat, masyarakatjustru memandang reklamasi dapat menurunkan nilai-nilai sosial-budaya, lingkungan, agama, dan adat istiadat Bali.

Isu rencana reklamasi Teluk Benoa ternyata muncul semenjak Desember 2012.Kemudian, mencuat ke media masa dan baru diketahui WALHI dengan ForBALI pada 26 Juni 2013.Di awali lewat 
munculnya SK bernomor 2138/02- reklamasi dimaksud telah dirancang di C/HK/2012, tentang izin dan hak kawasan Teluk Benoa.

pemanfaatan, pengembangan dan Situasidihadapi PT TWBI hingga pengelolaan wilayah perairan di Teluk akhir tahun 2018 belum menyelesaikan izin Benoa, lalu disusul SK bernomor 1727/01lingkungan atau AMDAL. PT TWBI $\mathrm{B} / \mathrm{HK} / 2013$ yang terbit atas permohonan investor PT TWBI dengan isi permohonan mereklamasi Teluk Benoa. Setelah itu, diterbitkan Perpres Nomor 51 Tahun 2014 tentang perubahan atas Perpres Nomor 45 Tahun 2011 tentang rencana tata ruang kawasan perkotaan Denpasar, Badung, Gianyar, dan Tabanan (Sarbagita).

Rencana menimbun di Teluk Benoa, melalui reklamasi baru diketahui, 26 Juni 2013. Pada saat itu, pesepak bola Negara Portugal asal dari klub Eropa raksasa Real Madrid, Cristiano Ronaldo datang ke Bali demi menanam bibit mangrove bersama Presiden keenam RI SBY. Ketika dilakukan acara penanaman bibit mangrove dimaksud muncullah kecurigaan dari WALHI Bali dan diketahuilah informasi ternyata megaproyek terganjal penyelesaian AMDAL akibat aspek sosial-budaya,sebab rencana reklamasi Teluk Benoa mendapat penolakanberbagai lapisan masyarakat Pasubayan Desa Adat, Non-Governmental Organization (NGO), dan gerakan BTR tersebut didukung para musisi indie.

Melalui demo BTR, masyarakat Bali mendorong presiden untuk mencabut Perpres Nomor 51 Tahun 2014 tentang Rencana Tata Ruang Kawasan Perkotaan Denpasar, Badung, Gianyar, dan Tabanan (Sarbagita) (www.cnnindonesia, 2016). Dalam Perpres itu, tercantum perubahan alih fungsi di kawasan Teluk Benoa yang semula dalamPerpres Nomor 45 Tahun 2011 adalah kawasan konservasi perairan pesisir Teluk Benoa menjadi zona pemanfaatan (Zona P) 
terbatas. Karena itu, perubahan alih fungsi kawasan lindung yang luasnya hampir 3 persen dari Pulau Bali atau sekitar 1.113 hektar mendapat penolakan dari masyarakat adat sekitar.

Penolakan reklamasi bukan hanya karena ada perubahan alih fungsi kawasan, tetapi karena penyimpangan, kerusakan alam, serta dampak sosial.Reklamasi Teluk Benoa adalah bentuk ketidakpatutan pemerintah terhadap masyarakat adat di Bali. Ketidakpatutan itu sebab pembangunan pulau-pulau reklamasi berada pada situs atau lokasi yang mana disucikan umat Hindu.

Secara teknis lapangan bahwa proyek reklamasidi Teluk Benoa memang belum dilaksanakan, belum ada pengerukan atau penimbunan tanah di areal sekitarTeluk Benoa, karena memang belum adanya izin pelaksanaan yang turun dari kementeriannya bagi pengembang. Rencana reklamasi masih dikaji untuk pemenuhan persyaratan dan izin dari kementerian, serta kajian AMDAL.

\section{Landasan Teori}

Tiga teori yang digunakan dalam penelitian ini, pertama, Teori Relasi dan Kuasa Pengetahuan Michel Foucault, bahwa tidak ada kekuasaan yang dimiliki secara keseluruhan di tangan satu orang sehingga ia dapat melakukannya sendiri terhadap orang lain secara total. Kekuasaan bagaikan sebuah mesin di mana setiap orang bisa saja terperangkap di dalamnya.Jumlah mereka yang menjalankan kekuasaan sebanyak yang dilakukan.Secara substansial, kekuasaan tidak lagi diidentifikasi sebagai hal terkait yang dimiliki atau dilakukan seseorang sebagai nasibnya sejak lahir; posisi tertentu menguasai dan mengizinkan efek supremasi kekuasaan diproduksi.

Kedua, Teori Praktik Pierre Bourdieu, di dalam kajian budaya, konsep praktik dianggap penting karena ia dikontraskan secara eksplisit maupun implisit dengan istilah bahasa, teks, atau wacana yang abstrak (disembodied). Pemikiran Bourdieu adalah tidak memisahkan teori serta praktik.Baginya, teks harus menjadi tindakan.Bourdieu juga berupaya mengolah teks pemikirannya lebih berpihak terhadap kelompok sosial yang tertindas atau terdominasi.

Ketiga, Teori Semiotik dari Terry Eagleton, semiotik merupakan studi terkait 
"sains" tentang tanda-tanda danpenandaan (signifikansi) yang dikembangkan dari karya dan pemikiran Saussure. Semiotik dipahami sebagai bentuk strukturalisme karena berupaya menjelaskan proses lahirnya makna dengan merujuk pada sistem perbedaan yang terstruktur di dalam bahasa. Pada teori semiotik, sistem penandaan seperti bahasa dipahami sebagai "pengaturan dan penataan" tanda-tanda yang membentuk makna dari dalam diri sendiri melalui serangkaian perbedaan konseptual dan bebunyian.

\section{Simpulan}

Penelitian ini menyimpulkan tiga buah hal; pertama,musisi musik indie dapat merangkul serta mampu untuk mengedukasi penggemar ke dalam gerakan perlawanan BTR. Kedua, gerakan BTR mencegah generasi ke depan terkena dampak dari kerusakanlingkungan alam seperti kasus

\section{Daftar Pustaka}

Barker,Chris. 2014. Kamus Kajian Budaya. Yogyakarta: PT Kanisius.

Bali Express. 2017. "Ini Dia 70 Titik Suci

Teluk Benoa; Tertuang dalam Tiga

Babad", sumber: https://www.jawap os.com/baliexpress/read/2017/10/08/ -18238/ini-dia-70-titik-suci-telukbenoa-tertuang-dalam-tigababad Diakses 7/07/2018

Bali Post. 2017. "Gelar Budaya Kesiman reklamasi Pulau Serangan. Ketiga, musik indie relevan memberimasukan sekaligus media kritik secara tidak langsung terhadap pemerintah.

\section{Saran}

Hasil penelitian dilakukan terdapat tiga saran; pertama, musik indie sebagai alat propaganda gerakan BTR. Musik indie mampu melecut sekaligus tidak membuat gerakan massa menjadi terkesan menoton. Kedua, gerakan BTR secara tegas menolak rencana reklamasi Teluk Benoa. Pemerintah terkait dapat duduk bersama mengambil solusi ke depan,baik nasib dan kealamiahan di Teluk Benoa. Ketiga, masyarakat Bali Selatan diharapkan tidak merasa asing di wilayahnya sendiri, tidak hanya berdiam diri, namun juga berani melawan hegemoni dari kapitalis yang bertujuan meminimalisir potensi alam dan adat istiadat budaya Bali.

Gelorakan Penolakan Reklamasi”, sumber: http://www.balipost.com/ne ws/2017/08/28/19679/Gelar-Budaya-

KesimanGelorakanPenolakan...html, Diakses 1/10/2017

Fashri, Fauzi. 2014. Pierre Bourdieu Menyingkap Kuasa Simbol. Yogyakarta:Jalasutra. ForBALI. 2017. "Kronologi BTR", sumber: www.forbali.org/id/kronologi-2/ Diakses 1/10/2017 
ForBALI. 2014. "Urgensi Menolak

Reklamasi Teluk Benoa", sumber: http://www.forbali.org/id/faq-2/

Diakses 1/07/2018ForBALI. 2017.

"Konser Mini Desa Adat Kelan", sumber: https://www.forbali.org/id/konser-mini-desa-adatkelan

Diakses 29/04/2018

Nariana, I Made. 2015. Manusia Bali dan

Reklamasi. Daerah Istimewa

Yogyakarta: Frame publishing.

Tantagode, Jube. 2008. Musik Underground

Indonesia: Revolusi Indie Label.

Yogyakarta: Harmoni. 